\title{
An EPQ Model for Deteriorating Production System and Items with Rework
}

\author{
N. Li, ${ }^{1}$ Felix T. S. Chan, ${ }^{1}$ S. H. Chung, ${ }^{1}$ and Allen H. Tai ${ }^{2}$ \\ ${ }^{1}$ Department of Industrial and Systems Engineering, The Hong Kong Polytechnic University, Hung Hom, Kowloon, Hong Kong \\ ${ }^{2}$ Department of Applied Mathematics, The Hong Kong Polytechnic University, Hung Hom, Kowloon, Hong Kong
}

Correspondence should be addressed to Felix T. S. Chan; f.chan@polyu.edu.hk

Received 7 December 2014; Accepted 5 February 2015

Academic Editor: Antonio Tornambe

Copyright (C) 2015 N. Li et al. This is an open access article distributed under the Creative Commons Attribution License, which permits unrestricted use, distribution, and reproduction in any medium, provided the original work is properly cited.

This paper investigates the economic production quantity model jointly considering product deterioration and a deteriorating production system with rework. In this imperfect deteriorating production system, not only does the machine produce defective product but also the machine is subjected to quality deterioration. To be more specific, the defective rate increases at certain time intervals. The defects produced are stored until the end of normal production process. Then they are reworked with extra cost to restore their quality and regarded as perfect product. The main objective is to minimize the total cost per unit product by determining the optimal combination of production run time and backlog quantity. Numerical experiments are carried out to illustrate the behavior of the inventory and show the impact of different parameters on the model. Discussion and conclusions are made at the end of the paper.

\section{Introduction}

Inventory control and management are crucial to the modern companies in order to survive in the competitive market. Too much inventory causes high inventory cost and low turnover rate, while having extremely low inventory level puts the company at the risk of losing incoming orders and customers [1]. For manufacturing companies, how many products to produce to meet the demand and keep the cost at low level is always a challenge. Economical production quantity (EPQ) is one of the classical problems in inventory control. The aim of this study is to identify the optimal stocking levels and production quantity to minimize the total cost generated. Nowadays the consideration of different demand type, product deterioration, production system reliability, and other uncertainties makes these classical problems even more complicated. In terms of product deterioration, perishable goods such as food, fruit, and drink and other products like electronic devices and metal processing are the good examples and their quality is heavily influenced by the storing condition and length of storage time after production. If the quality does not meet the standard or requirement anymore, either extra cost is needed to recover the quality or the product will be disposed of [2]
The reliability of production system, on the other hand, addresses the quality of production process such as defective rate, machine breakdown, and production speed. Defects can be generated from processing mistakes, setup mistakes, adjustment mistakes, and tools mistakes [3]. Although management techniques such as quality control and the improvement of manufacturing technology have successfully reduced the defect rate to a relatively low level, it is still a problem for companies, especially when the complexity of production is high. Mobile phone industry can be used as a good example for having extra cost caused by defects [4]. Similar to defective rate, the decrease of production and machine breakdown are also the obstacles to achieving a high productivity in a manufacturing system [5]. Maintenance is an effective method that prevents the serious machine breakdown and restores the production quality. But for deterioration within each production cycle, maintenance cannot solve the problem.

In academic world, the EPQ problem has attracted a large amount of researchers in the past 80 years. Goyal and Giri [6] have provided an in-depth overview of the literatures focusing on the deteriorating products. They have clearly defined the cause of product deterioration and categorized 
the different models used based on demand type, pricing policy, and so forth; interested reader can refer to it for more information. In 1993 Wee [7] first proposed an EPQ model with partial backlog and product deterioration and later he and Law [8] integrated the problem with the consideration of pricing policy in a finite planning horizon. Goyal and Gunasekaran [9] also combined the pricing problem with EPQ problem on deteriorating product. In addition, advertisement frequency is also considered in their model. The model with time-dependent deteriorating rate was developed by Manna and Chaudhuri [10] as an extension of previous works. In their research, not only is the deteriorating rate time-dependent but also the production rate is proportional to demand rate. All the previously mentioned research work assumed a continuous issuing policy to meet the demand of customers. Discontinuous issuing or delivery policy was taken into consideration by Chiu et al. [11]. Discontinuous issuing policy, as stated in their work, was more practical and common in the industry. In their paper, the delivery of products is divided into $n$ installments with a fixed time interval and quantity. Numerical methods were utilized to obtain the optimal solution. Later, they further looked at the discontinuous issuing EPQ problem with partial rework [12]. However in these two papers, the number of shipments is assumed to be known. Cardenas-Barron et al. [13] jointly considered the multidelivery EPQ problem with both lot size and number of deliveries to minimize the inventory cost. Backlog is also an important element in the traditional EPQ problem. Research works such as [14-18] have examined the EPQ problem with full/planned/partial backlog. Interested readers can refer to those papers for more details. Other similar works include Abad [19] and Sarkar [20].

For imperfect manufacturing system, Khouja and Mehrez [21] in 1994 stated that the previous research normally assumed constant production rate and perfect quality. In their work, an EPQ model with variable production rates and imperfect quality was developed where defective rate is the function of production speed. Kim and Hong [22] assumed that the machine changes from in-control to outcontrol state after a random period and defects are generated in out-control state. Chiu [15] further looked at the problem in which rework of defective products is carried out on the same machine and the impact of reworking on the EPQ model is investigated. Machine breakdown was also taken into consideration. The deterioration of production system was introduced by Lin and Kroll [23] and a timedependent defective rate was utilized to model the deterioration of machines. In recent studies, random defective rate [24], stochastic breakdown [25], stochastic demand, and maintenance scheduling [26] were also combined with the traditional EPQ problem.

The extant literatures show that majority of the papers have only considered either rework and imperfect system or the product deterioration. The few integrated studies can be found in the work of Teunter and Flapper [27], Inderfurth et al. [28], and Tai [29]. In the first paper, the rework and production were assumed to use the same machine and the defective rate follows a given probability distribution. The production quantity was desired to be determined to maximize the profit obtained. While in the second one, the model proposed in [28] generalized the problem, assuming the demand for good items is limited and the demand will be entirely satisfied. And also closed form results were obtained by utilizing constant and deterministic defective and deteriorating rate, while Tai [29] added inspection errors into the model with deteriorating items and imperfect production. In addition, he also investigated the effect of selling imperfect product to customer. However in all of the three studies mentioned above, the defective rate is regarded as stationary and it would not change along with time. In addition, backlog is not considered in the first two models. Hence as the main contribution of this paper, we model a single machine, single product EPQ problem with the joint consideration of deterioration of product and production systems with rework. Defective rate is assumed to be timedependent and backlog is allowed in the model. The effects of production deterioration on the system are investigated and analyzed.

The rest of the paper is arranged as follows. Section 2 introduces all the notations and assumptions used in this paper, while the detailed mathematical model is presented and elaborated in Section 3. Numerical experiments are included in Section 4 with sensitivity analysis followed by the conclusions in Section 5.

\section{Notations and Assumptions}

In this research, a production system with single machine and single product is modelled. In the system, the machine can conduct both production and rework process. The product is subjected to quality deterioration and the machine is assumed to be imperfect and deteriorating in terms of an increasing defective rate. The detailed assumptions made and the notations used in this paper are shown in the following subsections.

\subsection{Notations}

$\alpha_{i}$ : the defective rate of time period $i * \theta$;

$\theta$ : constant length between each change of defective rate (hour);

$\delta$ : deteriorating ratio;

$\mu$ : demand rate (unit/time);

$p$ : production rate (unit/time);

$p_{r}$ : rework rate (unit/time);

$M$ : the total number of intervals $\theta$ in normal production period;

$N$ : the total number of intervals $\theta$ in backlog period;

$C_{\mathrm{hp}}$ : holding cost of perfect products (\$/unit/time);

$C_{\mathrm{hi}}$ : holding cost of imperfect products (\$/unit/time);

$C_{\mathrm{dc}}$ : deteriorating cost (\$/unit);

$C_{p}$ : production cost (\$/unit);

$C_{p r}$ : rework cost (\$/unit);

$C_{b}$ : penalty cost for backlog (\$/unit/time); 
$C_{s}$ : fixed setup cost (\$/cycle);

$B$ : backlog quantity (unit);

Q: economic production quantity (unit);

$I_{s}$ : the inventory level at the end of normal production period (unit);

$I_{m}$ : the inventory level at the end of rework process (unit);

$I_{i} m$ : the inventory level of imperfect product (unit).

\subsection{Assumptions}

(1) Unsatisfied order will be backlogged and the backlog will be fulfilled at the beginning of the cycle.

(2) During the production period, the defective items are produced at a constant rate $\alpha_{i}$ in the time interval $[(i-1) \theta, i \theta), i \in \mathbb{N}$. We assume that the production system is deteriorating in the sense that the defective rate increases at time $i \times \theta, i \in \mathbb{N}$. Hence we have $\alpha_{1}<\alpha_{2}<\alpha_{3}<\cdots$. Through this paper, we consider a linear relation $\alpha_{i}=i \times \gamma$, where $\gamma$ is a constant.

(3) To reduce the complexity of the cost function, the normal production run time $T_{1}$ and the length of backlog period $T_{2}$ are assumed to be the integer multiple of $\theta$ since the value of $\theta$ is small.

(4) Maintenance is carried out after the whole production period, so at the beginning of each cycle, the defective rate is minimized.

(5) The imperfect products are reworked after the normal production process with an extra rework cost and the rework is assumed to be perfect.

(6) The deterioration only occurs to perfect products with a constant rate $\delta$.

(7) The deteriorated products are disposed of with cost.

(8) Demand rate $\mu$ is known and constant.

\section{Mathematical Modelling}

According to the assumptions and description of the production system, a mathematical model for the system has been formulated. The behaviour of the inventory level in one production cycle is shown in Figures 1 and 2 for perfect and imperfect products, respectively. As illustrated in Figure 1, the inventory level starts from backlog $B$ and the backlogged orders are satisfied first. During the first time interval $\theta$, the defective rate is maintained as $\alpha_{1}$. And at the end of the time interval, the defective rate increases to $\alpha_{2}$. After the backlog is made up, the production will be continued until the desired economical production quantity is achieved. All the imperfect products are reworked in $T_{3}$ and the whole production process is completed. In $T_{4}$ and $T_{5}$, the stocks are consumed by demand and backlog is generated during $T_{5}$. Similarly in Figure 2, the total amount of imperfect product piles up in periods $T_{1}$ and $T_{2}$ due to the defects produced. The gradient increases along with the rise of defective rate.

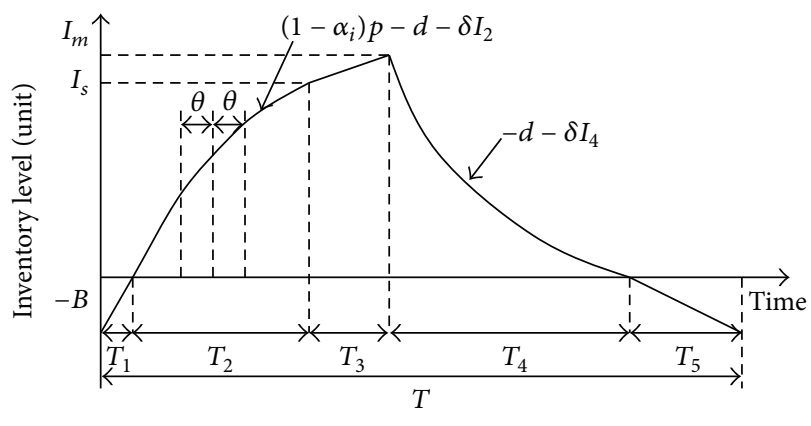

FIgURE 1: Inventory level of perfect items.

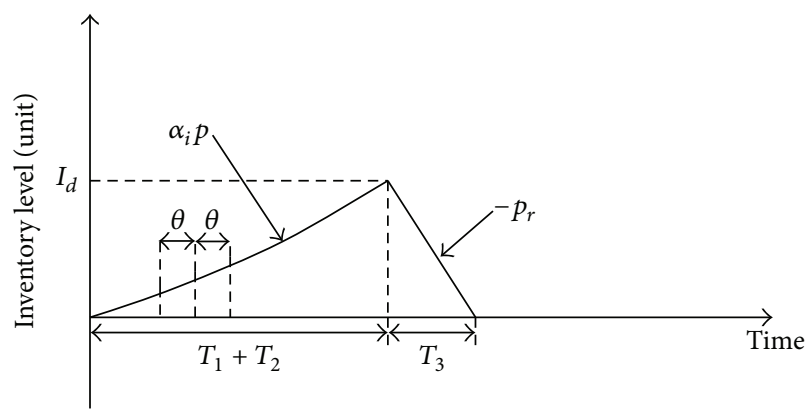

FIGURE 2: Inventory level of imperfect items.

So in general, the inventory level can be represented with the following equations.

For backlog period $0 \leq t_{1} \leq T_{1}$,

$$
I_{1}^{\prime}\left(t_{1}\right)=\left(1-\alpha_{i}\right) p-\mu, \quad(i-1) \theta \leq t_{1} \leq i \theta .
$$

For $i=1$,

$$
I_{1}\left(t_{1}\right)=\left(\left(1-\alpha_{1}\right) p-\mu\right) t_{1}-B, \quad 0 \leq t_{1} \leq \theta .
$$

Assume $\lambda_{i}=\left(1-\alpha_{i}\right) p-\mu$ for simplification and this will be used throughout the paper:

$$
I_{1}(\theta)=\lambda_{1} \theta-B .
$$

For $i=2, I_{2}(0)=I_{1}(\theta)=\lambda_{1} \theta-B$,

$$
I_{1}\left(t_{1}\right)=\lambda_{2} t_{1}+\lambda_{1} \theta-B, \quad \theta \leq t_{1} \leq 2 \theta .
$$

Similarly, the general inventory function in backlog period can be calculated as follows:

$$
\begin{aligned}
& I_{1}\left(t_{1}\right) \\
& = \begin{cases}\lambda_{1} t_{1}-B & 0 \leq t_{1} \leq \theta \\
\lambda_{2}\left(t_{1}-\theta\right)+\lambda_{1} \theta-B & \theta \leq t_{1} \leq 2 \theta \\
\vdots & \\
\lambda_{N}\left(t_{1}-(N-1) \theta\right)+\sum_{i=1}^{N-1} \lambda_{i} \theta-B & (N-1) \theta \leq t_{1} \leq T_{1} .\end{cases}
\end{aligned}
$$


For surplus stage, for the first period $\theta$, the inventory function is

$$
\begin{gathered}
I_{2}^{\prime}\left(t_{2}\right)=\lambda_{N}-\delta I_{2}\left(t_{2}\right), \quad 0 \leq t_{2} \leq \theta, \\
I_{2}\left(t_{2}\right)=\frac{\lambda_{N}}{\delta}\left(1-\exp \left(-\delta t_{2}\right)\right) \quad 0 \leq t_{2} \leq \theta .
\end{gathered}
$$

So for general surplus inventory function can be obtained:

$$
\begin{aligned}
& I_{2}\left(t_{2}\right) \\
& \begin{cases}\frac{\lambda_{N}}{\delta}\left(1-\exp \left(-\delta t_{2}\right)\right) & 0 \leq t_{2} \leq \theta \\
\frac{\lambda_{N}-\lambda_{N+1}}{\delta} \exp \left(-\delta t_{2}\right) & \\
\quad-\frac{\lambda_{N}}{\delta} \exp \left(-\delta t_{2}\right)+\frac{\lambda_{N}+1}{\delta} & \theta \leq t_{2} \leq 2 \theta \\
\vdots & \\
\sum_{j=1}^{M-N} \frac{\lambda_{N+j-1}-\lambda_{N+j}}{\delta} & \\
\cdot \exp \left(-\delta((i-j) \theta)+t_{2}\right) & \\
-\frac{\lambda_{N}}{\delta} \exp (-\delta((M-N-1) \theta & (M-1) \theta \leq t_{2} \leq T_{2} .\end{cases}
\end{aligned}
$$

The total production quantity can be calculated as

$$
p M \theta=Q \text {. }
$$

Hence the inventory level at the end of normal production $I_{s}=I_{2}\left(T_{2}\right)$ equals

$$
\begin{aligned}
I_{s}= & \sum_{j=1}^{M-N} \frac{\lambda_{N+j-1}-\lambda_{N+j}}{\delta} \\
& \cdot \exp (-\delta((M-N-j+1) \theta)) \\
& -\frac{\lambda_{N}}{\delta} \exp (-\delta((M-N) \theta))+\frac{\lambda_{M}}{\delta} .
\end{aligned}
$$

After the normal production process, the slope of inventory level can be represented with

$$
\begin{gathered}
I_{3}^{\prime}\left(t_{3}\right)=\left(p_{r}-\mu\right)-\delta I_{3}\left(t_{3}\right), \quad 0 \leq t_{3} \leq T_{3}, \\
I_{4}^{\prime}\left(t_{4}\right)=-\mu-\delta I_{4}\left(t_{4}\right), \quad 0 \leq t_{4} \leq T_{4}, \\
I_{5}^{\prime}\left(t_{5}\right)=-\mu, \quad 0 \leq t_{5} \leq T_{5} .
\end{gathered}
$$

According to the boundary conditions $I_{5}\left(T_{5}\right)=-B, I_{2}\left(T_{2}\right)=$ $I_{3}(0)=I_{s}, I_{3}\left(T_{3}\right)=I_{4}(0)=I_{m}$, and $I_{4}\left(T_{4}\right)=I_{5}(0)=0$, the inventory level can be obtained:

$$
\begin{gathered}
I_{3}\left(t_{3}\right)=\left(I_{s}-\frac{p_{r}-\mu}{\delta}\right) \exp \left(-\delta t_{3}\right)+\frac{p_{r}-\mu}{\delta}, \quad 0 \leq t_{3} \leq T_{3}, \\
I_{4}\left(t_{4}\right)=\left(I_{m}+\frac{\mu}{\delta}\right) \exp \left(-\delta t_{4}\right)-\frac{\mu}{\delta}, \quad 0 \leq t_{4} \leq T_{4}, \\
I_{5}\left(t_{5}\right)=-\mu t_{5}, \quad 0 \leq t_{5} \leq T_{5} .
\end{gathered}
$$

The maximum inventory level $I_{m}$ equals

$$
I_{m}=\left(I_{s}-\frac{p_{r}-\mu}{\delta}\right) \exp \left(-\delta T_{3}\right)+\frac{p_{r}-\mu}{\delta}
$$

and from (11) and $I_{4}\left(T_{4}\right)=0$

$$
I_{m}=\frac{\mu}{\delta}\left(\exp \left(\delta T_{4}\right)-1\right) .
$$

We can also find

$$
\sum_{i=1}^{N} \lambda_{i} \theta=d T_{5}=B
$$

For imperfect product, the inventory function in normal production time is

$$
\begin{aligned}
& I_{\text {im }}\left(t_{\text {im }}\right)=\sum_{1}^{i-1} \alpha_{i} \theta+\alpha_{i} t, \quad(i-1) \theta \leq t_{\text {im }} \leq i \theta, \\
& I_{i m}\left(t_{i m}\right)= \begin{cases}\alpha_{1} t_{i m} & 0 \leq t_{i m} \leq \theta \\
\alpha_{1} \theta+\alpha t_{i m} & \theta \leq t_{i m} \leq 2 \theta \\
\vdots & \\
\sum_{i=1}^{M-1} \alpha_{i} \theta+\alpha_{M} t_{i m} & (M-1) \theta \leq t_{i m} \leq T_{2}+T_{1} .\end{cases}
\end{aligned}
$$

The maximum number of imperfect products is

$$
I_{d}=\sum_{i=1}^{M} \alpha_{i} p \theta=p_{r} T_{3}
$$

With respect to total cost per unit product, it consists of 6 parts: holding cost for both perfect and imperfect products, backlog cost, deterioration cost, cost of production and rework, and lastly the fixed setup cost for each cycle run. And we aim to minimize the value of total cost per unit product:

$$
\mathrm{TC}=\frac{\left(\mathrm{PHC}+\mathrm{IHC}+\mathrm{BC}+\mathrm{DC}+\mathrm{PRC}+\mathrm{C}_{s}\right)}{\mathrm{Q}},
$$

whereas the holding cost of perfect product is

$$
\begin{gathered}
\text { PHC }=C_{\mathrm{hp}}\left[\int_{0}^{T_{2}} I_{2}\left(t_{2}\right) d t_{2}+\int_{0}^{T_{3}} I_{3}\left(t_{3}\right) d t_{3}\right. \\
\left.+\int_{0}^{T_{4}} I_{4}\left(t_{4}\right) d t_{4}\right] .
\end{gathered}
$$

The holding cost of imperfect products is

$$
\mathrm{IHC}=C_{\mathrm{hi}}\left[\int_{0}^{T_{1}+T_{2}} I_{i m}\left(t_{i m}\right) d t+\int_{0}^{T_{3}} I_{3}\left(t_{3}\right) d t_{3}\right] .
$$

The backlog cost is

$$
\mathrm{BC}=-C_{\mathrm{bc}}\left[\int_{0}^{T_{1}} I_{1}\left(t_{1}\right) d t_{1}+\int_{0}^{T_{5}} I_{5}\left(t_{5}\right) d t_{5}\right] .
$$


The deteriorating cost is

$$
\begin{aligned}
\mathrm{DC}= & C_{\mathrm{dc}}\left[\frac{1}{2} \lambda_{N} \theta+\sum_{i=N+1}^{M-1} \lambda_{i} \theta+\frac{1}{2} \lambda_{M} \theta-I_{s}\right] \\
& +C_{\mathrm{dc}}\left[\left(p_{r}-\mu\right) T_{3}-\left(I_{m}-I_{s}\right)\right] \\
& +C_{\mathrm{dc}}\left[I_{m}-d T_{4}\right] .
\end{aligned}
$$

The production and rework cost are

$$
\mathrm{PRC}=C_{p} \mathrm{Q}+C_{r} p_{r} T_{3}
$$

By substituting all the inventory functions into the cost equation, we get the following.

The perfect product inventory holding cost $\mathrm{PHC}$ is

$\mathrm{PHC}$

$$
\begin{gathered}
=C_{\mathrm{hp}} \sum_{i=1}^{M-N} \int_{0}^{\theta}\left[\sum_{j=1}^{i} \frac{\lambda_{N+j-1}-\lambda_{N+j}}{\delta} \exp \left(-\delta((i-j) \theta)+t_{2}\right)\right. \\
-\frac{\lambda_{N}}{\delta} \exp \left(-\delta\left((i-1) \theta+t_{2}\right)\right) \\
\left.+\frac{\lambda_{N+i}}{\delta}\right] d t \\
+C_{\mathrm{hp}}\left[\left(I_{s}-\frac{p_{r}-\mu}{\delta}\right)\left(\frac{1-\exp \left(-\delta T_{3}\right)}{\delta}\right)+\frac{(p r-\mu) T_{3}}{\delta}\right] \\
+C_{\mathrm{hp}}\left[\left(I_{m}-\frac{\mu}{\delta}\right)\left(\frac{1-\exp \left(-\delta T_{4}\right)}{\delta}\right)-\frac{\mu T_{4}}{\delta}\right] .
\end{gathered}
$$

The holding cost for imperfect product is

$$
\mathrm{IHC}=C_{\mathrm{hi}}\left[\sum_{i=1}^{M}\left(\sum_{j=1}^{i} \alpha_{j} \theta^{2}+\frac{1}{2} \alpha_{i} \theta^{2}\right)+\frac{1}{2} p_{r} T_{3}^{2}\right] .
$$

The backlog cost is

$$
\begin{aligned}
\mathrm{BC}= & -C_{\mathrm{bc}}\left[\int_{0}^{\theta}\left(\lambda_{1} t-B\right) d t\right] \\
& -C_{\mathrm{bc}} \sum_{i=1}^{N}\left[\int_{0}^{\theta}\left(\left(\sum_{j=1}^{i-1} \lambda_{i} \theta-B\right) \theta+\lambda_{i} t\right) d t\right] \\
& -C_{\mathrm{bc}}\left[-\frac{1}{2} \mu T_{5}^{2}\right] .
\end{aligned}
$$

The deteriorating cost is

$$
\begin{aligned}
\mathrm{DC}=C_{\mathrm{dc}} & {\left[\left(\sum_{i=N+1}^{M} \lambda_{i} \theta\right)-I_{s}+\left(p_{r}-\mu\right) T_{3}\right.} \\
& \left.-\left(I_{m}-I_{s}\right)+I_{m}-d T_{4}\right] .
\end{aligned}
$$

In order to minimize the total cost per product, the optimal combination of $M$ and $N$ is desired to be determined. So the relationship among $M, N$, and other variables such as time $T_{i}$ and back $\log B$ is essential to solve the problem. First of all, according to the assumption, $T_{1}$ and $T_{2}$ can be represented by

$$
\begin{gathered}
T_{1}=\theta N, \\
T_{2}=\theta(M-N) .
\end{gathered}
$$

Also since the defective rate is linearly increasing with a constant rate $\gamma$, we have

$$
\alpha_{i}=\gamma * i \quad \text { for } i \in[0, M] .
$$

Hence

$$
\begin{gathered}
\lambda_{i}=p-\mu-\gamma p i, \\
\lambda_{i}-\lambda_{i+1}=\gamma p .
\end{gathered}
$$

According to (18) and (30), we could have

$$
T_{3}=\frac{\gamma p \theta(M+1)^{2}}{2 p_{r}} .
$$

Substituting (30) into (9), we could obtain the following equation:

$$
\begin{aligned}
I_{s}= & \frac{\gamma p}{\delta} \sum_{j=1}^{M-N} \exp \left((-\delta(M-N-j+1) \theta)+\frac{1}{2} \theta\right) \\
& -\frac{(1-\gamma N) p-\mu}{\delta} \exp (-\delta(M-N) \theta) \\
& +\frac{(1-\gamma M) p-\mu}{\delta} .
\end{aligned}
$$

The above expression can be simplified by using the Taylor series approximation under the assumptions that $\delta(M-N)$, $\delta T_{3}$, and $\delta T_{4}$ are small. This approach can also be found in other research work on deteriorating product such as [7, 29]. So,

$$
\begin{aligned}
& \exp (-\delta(M-N-j+1) \theta) \\
& \approx 1-\delta(M-N-j+1) \theta+\frac{1}{2}(\delta(M-N-j+1) \theta)^{2} \\
& \quad \exp \left(-\delta T_{3}\right) \approx 1-\delta T_{3}+\frac{1}{2}\left(\delta T_{3}\right)^{2} \\
& \exp \left(-\delta T_{4}\right) \approx 1-\delta T_{4}+\frac{1}{2}\left(\delta T_{4}\right)^{2}
\end{aligned}
$$

We could simplify the equation of $I_{s}$ and $I_{m}$ based on (33) and (14):

$$
\begin{aligned}
I_{s}= & \theta(M-N)\left(p-\mu-\frac{\gamma p}{2}(M+N+1)\right), \\
I_{m}= & \theta(M-N)\left(p-\mu-\frac{\gamma p}{2}(M+N+1)\right) \\
& \left(1-\frac{\delta \gamma p \theta M^{2}}{2 p_{r}}\right)+\left(p_{r}-\mu\right) \frac{\gamma p \theta M^{2}}{2 p_{r}} .
\end{aligned}
$$


Since $I_{m}$ can also be represented with (15), $T_{4}$ can also be determined with (15) and (36)

$$
\begin{array}{r}
T_{4}=\frac{1}{\mu}\left[\theta(M-N)\left(p-\mu-\frac{\gamma p}{2}(M+N+1)\right)\right. \\
\left.\cdot\left(1-\frac{\delta \gamma p \theta M^{2}}{2 p_{r}}\right)+\left(p_{r}-\mu\right) \frac{\gamma p \theta M^{2}}{2 p_{r}}\right] .
\end{array}
$$

According to (16) $B$ can be expressed as

$$
\begin{gathered}
B=\left(p-d-\frac{1}{2} \gamma p N\right) \theta N, \\
T_{5}=\frac{(p-d-(1 / 2) \gamma p N) \theta N}{\mu} .
\end{gathered}
$$

Deteriorating cost is reduced to

$$
\begin{aligned}
\mathrm{DC}=C_{\mathrm{dc}}[ & (p-\mu)(M-N) \theta-\gamma p \theta \frac{(M-N)(M-N-1)}{2} \\
& \left.+p_{r} T_{3}-d T_{4}\right] .
\end{aligned}
$$

Backlog cost is

$$
\begin{aligned}
\mathrm{BC}=-C_{b} & {\left[\frac{1}{2}(p-\mu) N^{2} \theta^{2}-\frac{1}{12} \gamma p \theta^{2}(N-1)(2 N+5) N\right.} \\
& \left.-B \theta N-\frac{1}{2} d T 5^{2}\right] .
\end{aligned}
$$

Holding cost for perfect product is

$$
\begin{aligned}
& \text { PHC }=C_{\mathrm{hp}}\left[\frac{1}{2}(p-\mu-\gamma p N) \theta^{2}\right. \\
& \cdot((M-N)(M-N+1)-1) \\
& \quad-\frac{1}{12} \gamma p \theta^{2}(2 M-2 N+1) \\
& \cdot(M-N)(M-N+1) \\
& \left.+I_{s}\left(T_{3}-\frac{1}{2} \delta T_{3}^{2}\right)+\frac{1}{2}\left(p_{r}-\mu\right) T_{3}^{2}+\frac{1}{2} d T_{4}^{2}\right], \\
& \text { IHC }=C_{\mathrm{hi}}\left[\frac{1}{12} \gamma p \theta^{2} M(M+1)(2 M+3)\right. \\
& \left.+\frac{1}{2} \gamma p \theta M^{2} T_{3}-\frac{1}{2} p T_{3}^{2}\right] .
\end{aligned}
$$

Lastly by substituting $T_{1}, T_{2}, T_{3}, T_{4}, T_{5}, B$, and $Q$ with $M$ and $N$, the cost function can be further reduced. The overall total cost per unit product is obtained. To be noticed, the items with second or higher order $\delta$ and $\gamma$ have been removed in order to simplify the equation:

$$
\begin{aligned}
\mathrm{TC}= & A_{1}+\frac{A_{2}}{M}+A_{3} M+A_{4} M^{2}+A_{5} M^{3}+A_{6} \frac{N^{3}}{M} \\
& +A_{7} N^{2}+A_{8} \frac{N^{2}}{M}+A_{9} N^{2} M \\
& +A_{10} N+A_{11} \frac{N}{M}+A_{12} N M+A_{13} N M^{2},
\end{aligned}
$$

where

$$
\begin{aligned}
& A_{1}=C_{p}+\frac{C_{\mathrm{hp}} \theta}{2}\left(\theta-\frac{\mu}{p}-\frac{\gamma}{6}\right)+\frac{C_{\mathrm{hi}} \gamma \theta}{4}, \\
& A_{2}=\frac{C_{s}}{p \theta}-\frac{C_{\mathrm{hp}} \theta}{2}\left(1-\frac{\mu}{p}\right) \text {, } \\
& A_{3}=\frac{C_{r} \gamma}{2}+\frac{5 C_{\mathrm{hi}} \gamma \theta}{12}+\frac{C_{\mathrm{hp}} \theta}{2}\left(\frac{\gamma}{2}-\frac{p \gamma}{\mu}-\frac{1}{2}+\frac{p}{2 \mu}\right) \text {, } \\
& A_{4}=\frac{C_{\mathrm{hi}} \gamma \theta}{6}-\frac{C_{\mathrm{hp}} \gamma \theta}{6}-\frac{C_{\mathrm{dc}} \mu \gamma \delta \theta}{2 p_{r}}(\mu-p) \text {, } \\
& A_{5}=\frac{C_{\mathrm{hp}} \gamma \delta \theta^{2}}{p_{r}}\left(p-\frac{\mu}{2}-\frac{p^{2}}{2 \mu}\right) \text {, } \\
& A_{6}=\frac{\gamma \theta}{2}\left(\frac{1}{3}-\frac{p}{\mu}\right)\left(C_{b}+C_{\mathrm{hp}}\right) \text {, } \\
& A_{7}=\frac{C_{\mathrm{hp}} p \gamma \theta}{2 \mu} \text {, } \\
& A_{8}=C_{\mathrm{dc}} \gamma+\frac{C_{b} \theta}{2}\left(\frac{\gamma}{2}-1+\frac{p}{\mu}\right) \\
& +\frac{C_{\mathrm{hp}} \theta}{2}\left(\frac{p}{\mu}+\frac{3 \gamma}{2}-\frac{p \gamma}{\mu}-1\right), \\
& A_{9}=\frac{C_{\mathrm{hp}} \gamma \delta \theta^{2}}{p_{r}}\left(p-\frac{\mu}{2}-\frac{p^{2}}{\mu}\right) \text {, } \\
& A_{10}=C_{\mathrm{dc}} \gamma+C_{\mathrm{hp}} \theta\left(\frac{p}{\mu}-1\right)(\gamma-1) \text {, } \\
& A_{11}=\frac{C_{\mathrm{hp}} \theta}{2}\left(\frac{\mu}{p}+\frac{7 \gamma}{6}-1\right)-\frac{5 C_{b} \gamma \theta}{12} \\
& A_{12}=\frac{C_{\mathrm{dc}} \gamma \delta \theta}{2 p_{r}}(\mu-p) \text {, } \\
& A_{13}=\frac{C_{\mathrm{hp}} \gamma \delta \theta^{2}}{p_{r}}\left(\mu-p+\frac{p^{2}}{\mu}\right) .
\end{aligned}
$$

For optimum values of $T C(N, M)$, we make $\partial T C(N$, $M) / \partial N=0$ and $\partial T C(N, M) / \partial M=0$ which is equivalent to

$$
\begin{aligned}
3 A_{6} \frac{N^{2}}{M} & +2 A_{7} N+2 A_{8} \frac{N}{M}+2 A_{9} N M+A_{10} \\
& +A_{11} \frac{1}{M}+A_{12} M+A_{13} M^{2}=0,
\end{aligned}
$$




$$
\begin{aligned}
A_{3}-\frac{A 2}{M^{2}}+2 A_{4} M+3 A_{5} M^{2}+2 A_{1} 2 N+A_{11} \frac{N}{M^{2}} \\
+2 A_{13} M N+A_{9} N^{2}-A_{*} \frac{N^{2}}{M^{2}}-A_{6} \frac{N^{3}}{M^{2}}=0 .
\end{aligned}
$$

The corresponding Hessian matrix is shown below:

$$
H=\left(\begin{array}{ll}
H_{1} & H_{2} \\
H_{2} & H_{3}
\end{array}\right)
$$

where

$$
\begin{gathered}
H_{1}=2 A_{4}+\frac{2 A_{2}}{M^{3}}+6 A_{5} M+2 A_{1} 3 N \\
+\frac{2 A_{11} N}{M^{3}}+\frac{2 A_{8} N^{2}}{M^{3}}+\frac{2 A_{6} N^{3}}{M^{3}}, \\
H_{2}=A_{12}-\frac{A_{11}}{M^{2}}+2 A_{13} M+2 A_{9} N-\frac{2 A_{8} N}{M^{2}}-\frac{3 A_{6} N^{2}}{M^{2}} \\
H_{3}=2 A_{7}+\frac{2 A_{8}}{M}+2 A_{9} M+\frac{6 A_{6} N}{M} .
\end{gathered}
$$

According to the optimum condition if the second order partial derivative for $M$ and $N$ is positive, then the hessian matrix is positive definite and the minimum total cost can be found. However, due to the complexity of the cost function, an explicit solution cannot be obtained. Instead, we will use numerical examples to illustrate that the cost function is convex and the optimum result is also determined accordingly.

\section{Numerical Experiment}

Numerical examples and sensitivity are conducted in the following section. To be more specific, first of all, the plots generated for cost function are used to demonstrate that the cost function is convex. And then sensitivity analysis indicates the impact of different parameters on the overall inventory performance.

4.1. Numerical Examples. In these examples, the values of the parameters are assumed as follows: $\gamma=0.01, \theta=0.01, \delta=$ $0.1, C_{\mathrm{hp}}=\$ 40, C_{\mathrm{hi}}=\$ 30, C_{p}=\$ 100 ; C_{r}=\$ 40, C_{b}=\$ 60$, $C_{\mathrm{dc}}=\$ 60, \mu=100, p=600$, and $p_{r}=300$. The optimum combination of $N$ and $M$ is $\left(N^{*}, M^{*}\right)=(4,10)$.

As shown in Figure 3, the cost function shows its convexity and the optimum pair of $\left(N^{*}, M^{*}\right)$ is the lowest point, while, in Figures 4(a) and 4(b), the convexity is more clear when $M$ and $N$ are fixed at its optimum value, respectively. Hence the optimal $T_{1}^{*}, T_{2}^{*}, T_{3}^{*}, T_{4}^{*}, T_{5}^{*}$, and $T^{*}$ are calculated as

$$
\begin{gathered}
T_{1}^{*}=0.04, \quad T_{2}^{*}=0.06, \\
T_{3}^{*}=0.01, \quad T_{4}^{*}=0.293, \\
T_{5}^{*}=0.195 .
\end{gathered}
$$

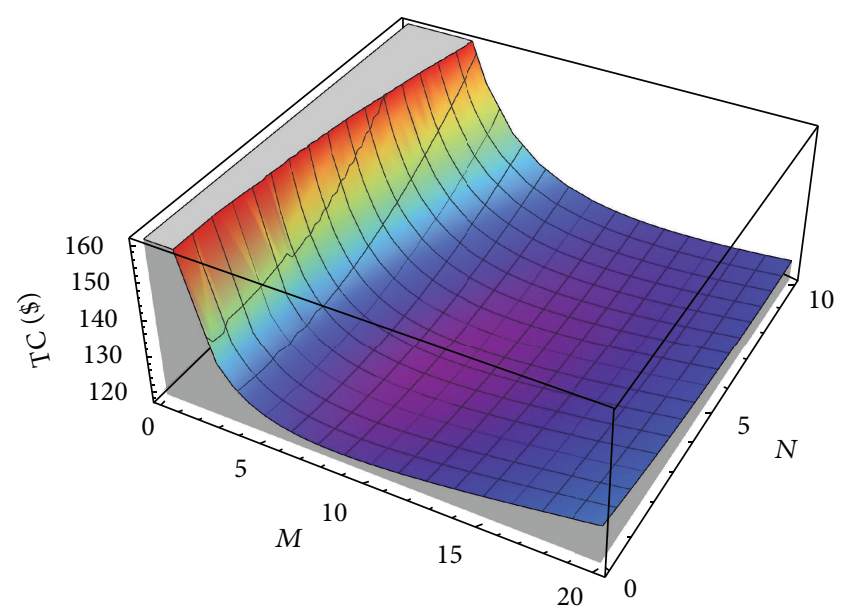

Figure 3: The plot of total cost per unit product against $M$ and $N$.

The optimal production quantity and backlog quantity are determined as

$$
Q^{*} \approx 60, \quad B^{*} \approx 20 .
$$

The optimal total cost per unit product, the optimum production run time, and the optimal cycle time are

$$
\mathrm{TC}^{*}=118.479, \quad T_{1}^{*}+T_{2}^{*}=0.1, \quad T^{*}=0.598 .
$$

4.2. Sensitivity Analysis. The sensitivity analysis for the parameters is conducted and the results and discussion are listed down below. As shown in Tables 1 and 2, for each of the parameters, four more experiments are carried out with the changes of $-50 \%,-25 \%, 25 \%$, and $50 \%$. The corresponding optimal values of total cost per unit product, $M$ and $N$, are presented in the tables. To be noticed, the values of $M$ and $N$ are interpreted as the production run time and backlog quantity, respectively, in the discussion since they have positive relationship.

For the key parameters, consider the following.

(i) Both the parameters $\theta$ and $\gamma$, which are related to the imperfect production system, have significant impact on the total cost per unit product. The increment of $\theta$ reduces the cost, while, for $\gamma$, the lower the value is, the lower the cost is. It means that slow deterioration of production quality or relatively steady defective rate helps cut down the total cost per unit product. In addition, high $\gamma$ shortens production run time which is represented by $M$.

(ii) The deterioration of product has positive relationship with the total cost per unit product. But when compared with $\theta$ and $\gamma$, its influence on the overall system is relatively smaller.

(iii) The total cost per unit product is especially sensitive to the changes of demand rate $\mu$. With the rise of $\mu$, the cost drops rapidly while the total production run time $M \theta$ increases instead. The value of $M$ is heavily influenced by the production rate. During 


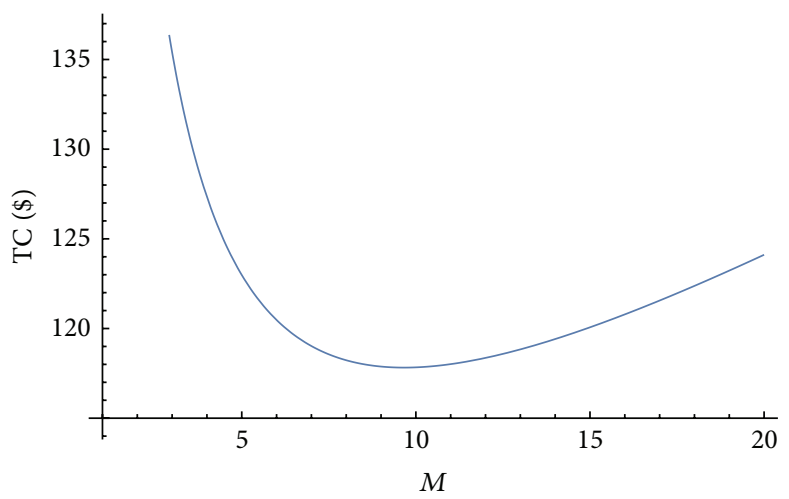

(a) TC against $M$

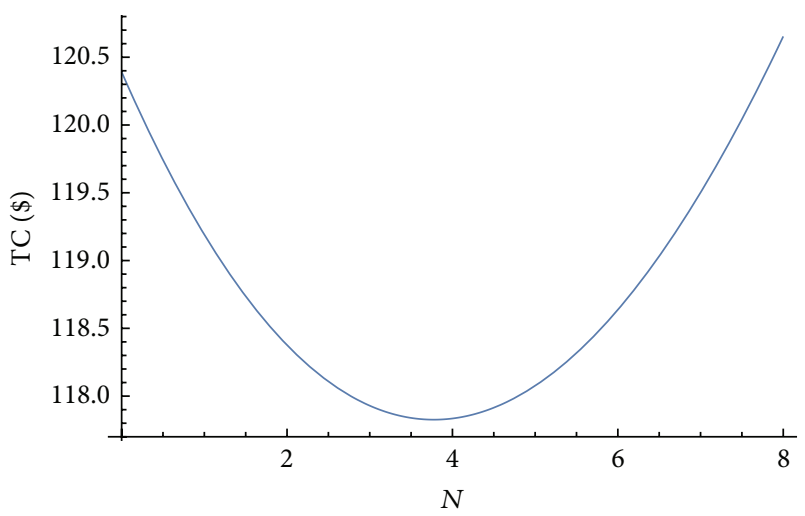

(b) TC against $M$

Figure 4: Total cost per unit product against $M$ and $N$.

TABLE 1: The sensitivity analysis for different key parameters.

\begin{tabular}{|c|c|c|c|c|c|c|}
\hline \multirow{2}{*}{ Parameter } & \multirow{2}{*}{ Optimal values } & \multicolumn{5}{|c|}{ Changes } \\
\hline & & $-50 \%$ & $-25 \%$ & $0 \%$ & $25 \%$ & $50 \%$ \\
\hline \multirow{3}{*}{$\theta$} & $\mathrm{TC}^{*}$ & 120.68 & 118.824 & 117.835 & 117.16 & 116.765 \\
\hline & $M^{*}$ & 16 & 12 & 10 & 8 & 7 \\
\hline & $N^{*}$ & 5 & 4 & 4 & 3 & 3 \\
\hline \multirow{3}{*}{$\gamma$} & $\mathrm{TC}^{*}$ & 116.116 & 116.977 & 117.835 & 118.569 & 119.327 \\
\hline & $M^{*}$ & 10 & 10 & 10 & 9 & 9 \\
\hline & $N^{*}$ & 4 & 4 & 4 & 3 & 3 \\
\hline \multirow{3}{*}{$\delta$} & $\mathrm{TC}^{*}$ & 117.824 & 117.829 & 117.835 & 117.84 & 117.846 \\
\hline & $M^{*}$ & 10 & 10 & 10 & 10 & 10 \\
\hline & $N^{*}$ & 4 & 4 & 4 & 4 & 4 \\
\hline \multirow{3}{*}{$\mu$} & $\mathrm{TC}^{*}$ & 124.166 & 120.033 & 117.835 & 116.399 & 115.43 \\
\hline & $M^{*}$ & 8 & 9 & 10 & 10 & 10 \\
\hline & $N^{*}$ & 4 & 3 & 4 & 4 & 3 \\
\hline \multirow{3}{*}{$p$} & $\mathrm{TC}^{*}$ & 119.664 & 118.479 & 117.835 & 117.563 & 117.193 \\
\hline & $M^{*}$ & 17 & 12 & 10 & 9 & 6 \\
\hline & $N^{*}$ & 4 & 4 & 4 & 3 & 2 \\
\hline \multirow{3}{*}{$p_{r}$} & $\mathrm{TC}^{*}$ & 117.817 & 117.832 & 117.835 & 117.841 & 117.842 \\
\hline & $M^{*}$ & 10 & 10 & 10 & 10 & 10 \\
\hline & $N^{*}$ & 4 & 4 & 4 & 4 & 4 \\
\hline
\end{tabular}

the increase of production rate, $M$ declines from 17 to as low as 6 . On the contrary, the influence brought by remanufacturing rate is not obvious.

For the cost parameters, consider the following.

(i) High holding cost $C_{\mathrm{hp}}$ causes the increase of backlog quantity and decrease of holding quantity; meanwhile the value of backlog quantity drops significantly along with the increase of backlog $\operatorname{cost} C_{b}$.

(ii) The total cost per unit product is affected by the production cost to a large extent. But it does not change the production run time and backlog quantity.

(iii) Both the production run time and the backlog quantity grow with higher setup cost $C_{s}$. The total cost per unit product is also sensitive to the changes of setup cost.

\section{Conclusions}

In this paper, a modified EPQ model with rework and backlog has been proposed. Compared with the existing works, the deterioration of product and production process is taken into account at the same time which is the main contribution to this research field. To model the deterioration of production process, we assume that the defective rate increases at constant intervals. Defective products are reworked at the end of normal production process and the rework is viewed as perfect process. In order to minimize the total cost per unit product, the optimal pair of the total number 
TABLE 2: The sensitivity analysis for different unit costs.

\begin{tabular}{|c|c|c|c|c|c|c|}
\hline \multirow{2}{*}{ Unit cost } & \multirow{2}{*}{ Optimal values } & \multicolumn{5}{|c|}{ Changes } \\
\hline & & $-50 \%$ & $-25 \%$ & $0 \%$ & $25 \%$ & $50 \%$ \\
\hline \multirow{3}{*}{$C_{\mathrm{hp}}$} & $\mathrm{TC}^{*}$ & 115.054 & 116.687 & 117.835 & 118.593 & 119.234 \\
\hline & $M^{*}$ & 11 & 10 & 10 & 9 & 9 \\
\hline & $N^{*}$ & 2 & 3 & 4 & 4 & 5 \\
\hline \multirow{3}{*}{$C_{\mathrm{hi}}$} & $\mathrm{TC}^{*}$ & 117.764 & 117.819 & 117.835 & 117.851 & 117.866 \\
\hline & $M^{*}$ & 10 & 10 & 10 & 10 & 10 \\
\hline & $N^{*}$ & 4 & 4 & 4 & 4 & 4 \\
\hline \multirow{3}{*}{$C_{\mathrm{dc}}$} & $\mathrm{TC}^{*}$ & 117.07 & 117.421 & 117.835 & 118.035 & 118.42 \\
\hline & $M^{*}$ & 10 & 10 & 10 & 10 & 9 \\
\hline & $N^{*}$ & 4 & 4 & 4 & 3 & 3 \\
\hline \multirow{3}{*}{$C_{p}$} & $\mathrm{TC}^{*}$ & 67.803 & 92.8032 & 117.835 & 142.898 & 171.433 \\
\hline & $M^{*}$ & 10 & 10 & 10 & 10 & 10 \\
\hline & $N^{*}$ & 4 & 4 & 4 & 4 & 4 \\
\hline \multirow{3}{*}{$C_{p r}$} & $\mathrm{TC}^{*}$ & 116.803 & 117.303 & 117.835 & 118.303 & 118.753 \\
\hline & $M^{*}$ & 10 & 10 & 10 & 10 & 9 \\
\hline & $N^{*}$ & 4 & 4 & 4 & 4 & 4 \\
\hline \multirow{3}{*}{$C_{b}$} & $\mathrm{TC}^{*}$ & 116.11 & 117.19 & 117.835 & 118.202 & 118.515 \\
\hline & $M^{*}$ & 10 & 10 & 10 & 9 & 9 \\
\hline & $N^{*}$ & 7 & 5 & 4 & 3 & 2 \\
\hline \multirow{3}{*}{$C_{s}$} & $\mathrm{TC}^{*}$ & 111.898 & 114.556 & 117.835 & 119.908 & 121.802 \\
\hline & $M^{*}$ & 7 & 9 & 10 & 11 & 11 \\
\hline & $N^{*}$ & 3 & 3 & 4 & 4 & 4 \\
\hline
\end{tabular}

of intervals $\theta$ in normal period $M$ and in backlog period $N$ is determined. Due to the high complexity of the cost function, we cannot prove the convexity of the function in the analytical way. Instead numerical experiments are carried out to illustrate the convexity of the cost function and to find the optimal solution. The impact of all the different parameters on the system is provided and summarized in Sensitivity Analysis. In terms of future research, the current model can be extended in several directions. First of all, at present the system deterioration rate is assumed to be linear in this research work. So a more general exploration of other types of deterioration rate can be done to test the performance of the proposed method. Secondly, machine breakdown can be added into the model to make the model more practical, in which machines subject to failures and production process are stopped once the machine is broken. And also the model can be generalized into both multiproduction and rework periods model and multiproduct/multimachine model. Lastly stochastic demand and partial backlog can also be introduced into the current work.

\section{Conflict of Interests}

The authors declare that there is no conflict of interests regarding the publication of this paper.

\section{Acknowledgments}

The work described in this paper was substantially supported by a grant from the Research Grants Council of the Hong
Kong Special Administrative Region, China (Project no. PolyU 510311); a grant from The Natural Science Foundation of China (Grant no. 71471158); and The Hong Kong PhD Fellowship Scheme under Project Code 1-904Z/Student Account Code RUYF.

\section{References}

[1] D. Walters, Inventory Control and Management, Wiley India, New Delhi, India, 2008.

[2] F. Raafat, "Survey of literature on continuously deteriorating inventory models," Journal of the Operational Research Society, vol. 42, no. 1, pp. 27-37, 1991.

[3] C. M. Hinckley, "Defining the best quality-control systems by design and inspection," Clinical Chemistry, vol. 43, no. 5, pp. 873-879, 1997.

[4] T. Worstall, "The high cost to Foxconn of returned apple iphones," Forbes, 2013, http://www.forbes.com/sites/timworstall/ 2013/04/22/the-high-cost-to-foxconn-of-returned-apple-iphones/.

[5] S. M. R. Iravani and I. Duenyas, "Integrated maintenance and production control of a deteriorating production system," IIE Transactions, vol. 34, no. 5, pp. 423-435, 2002.

[6] S. K. Goyal and B. C. Giri, "Recent trends in modeling of deteriorating inventory," European Journal of Operational Research, vol. 134, no. 1, pp. 1-16, 2001.

[7] H.-M. Wee, "Economic production lot size model for deteriorating items with partial back-ordering," Computers and Industrial Engineering, vol. 24, no. 3, pp. 449-458, 1993.

[8] H.-M. Wee and S.-T. Law, "Economic production lot size for deteriorating items taking account of the time-value of money," 
Computers and Operations Research, vol. 26, no. 6, pp. 545-558, 1999.

[9] S. K. Goyal and A. Gunasekaran, "An integrated productioninventory-marketing model for deteriorating items," Computers and Industrial Engineering, vol. 28, no. 4, pp. 755-762, 1995.

[10] S. K. Manna and K. S. Chaudhuri, "An EOQ model with ramp type demand rate, time dependent deterioration rate, unit production cost and shortages," European Journal of Operational Research, vol. 171, no. 2, pp. 557-566, 2006.

[11] S. W. Chiu, K.-K. Chen, and H.-D. Lin, "Numerical method for determination of the optimal lot size for a manufacturing system with discontinuous issuing policy and rework," International Journal for Numerical Methods in Biomedical Engineering, vol. 27, no. 10, pp. 1545-1557, 2011.

[12] S. W. Chiu, Y.-S. P. Chiu, and J.-C. Yang, "Combining an alternative multi-delivery policy into economic production lot size problem with partial rework," Expert Systems with Applications, vol. 39, no. 3, pp. 2578-2583, 2012.

[13] L. E. Cardenas-Barron, B. Sarkar, and G. Trevino-Garza, "An improved solution to the replenishment policy for the EMQ model with rework and multiple shipments," Applied Mathematical Modelling: Simulation and Computation for Engineering and Environmental Systems, vol. 37, no. 7, pp. 5549-5554, 2013.

[14] L. E. Cárdenas-Barrón, "The economic production quantity (EPQ) with shortage derived algebraically," International Journal of Production Economics, vol. 70, no. 3, pp. 289-292, 2001.

[15] Y. P. Chiu, "Determining the optimal lot size for the finite production model with random defective rate, the rework process, and backlogging," Engineering Optimization, vol. 35, no. 4, pp. 427-437, 2003.

[16] L. E. Cárdenas-Barrón, "Economic production quantity with rework process at a single-stage manufacturing system with planned backorders," Computers and Industrial Engineering, vol. 57, no. 3, pp. 1105-1113, 2009.

[17] D. W. Pentico, M. J. Drake, and C. Toews, "The deterministic EPQ with partial backordering: a new approach," Omega, vol. 37, no. 3, pp. 624-636, 2009.

[18] A. Eroglu and G. Ozdemir, "An economic order quantity model with defective items and shortages," International Journal of Production Economics, vol. 106, no. 2, pp. 544-549, 2007.

[19] P. L. Abad, "Optimal pricing and lot-sizing under conditions of perishability, finite production and partial backordering and lost sale," European Journal of Operational Research, vol. 144, no. 3, pp. 677-685, 2003.

[20] B. Sarkar, "A production-inventory model with probabilistic deterioration in two-echelon supply chain management," Applied Mathematical Modelling, vol. 37, no. 5, pp. 3138-3151, 2013.

[21] M. Khouja and A. Mehrez, "Economical production lot size model with variable production rate and imperfect quality," The Journal of the Operational Research Society, vol. 45, no. 12, pp. 1405-1417, 1994.

[22] C. H. Kim and Y. Hong, "An optimal production run length in deteriorating production processes," International Journal of Production Economics, vol. 58, no. 2, pp. 183-189, 1999.

[23] G. C. Lin and D. E. Kroll, "Economic lot sizing for an imperfect production system subject to random breakdowns," Engineering Optimization, vol. 38, no. 1, pp. 73-92, 2006.

[24] B. Sarkar, L. E. Cárdenas-Barrón, M. Sarkar, and M. L. Singgih, "An economic production quantity model with random defective rate, rework process and backorders for a single stage production system," Journal of Manufacturing Systems, vol. 33, no. 3, pp. 423-435, 2014.

[25] Y.-S. P. Chiu and H.-H. Chang, "Optimal run time for EPQ model with scrap, rework and stochastic breakdowns: a note," Economic Modelling, vol. 37, pp. 143-148, 2014.

[26] B. Pal, S. S. Sana, and K. Chaudhuri, "A mathematical model on EPQ for stochastic demand in an imperfect production system," Journal of Manufacturing Systems, vol. 32, no. 1, pp. 260-270, 2013.

[27] R. H. Teunter and S. D. P. Flapper, "Lot-sizing for a single-stage single-product production system with rework of perishable production defectives," OR Spectrum: Quantitative Approaches in Management, vol. 25, no. 1, pp. 85-96, 2003.

[28] K. Inderfurth, G. Lindner, and N. P. Rachaniotis, "Lot sizing in a production system with rework and product deterioration," International Journal of Production Research, vol. 43, no. 7, pp. 1355-1374, 2005.

[29] A. H. Tai, "Economic production quantity models for deteriorating/imperfect products and service with rework," Computers and Industrial Engineering, vol. 66, no. 4, pp. 879-888, 2013. 


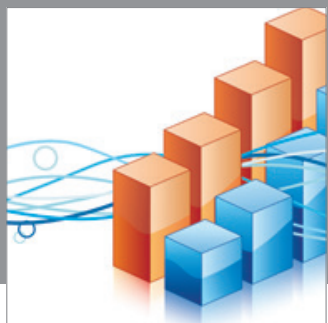

Advances in

Operations Research

mansans

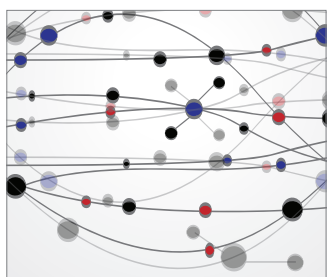

The Scientific World Journal
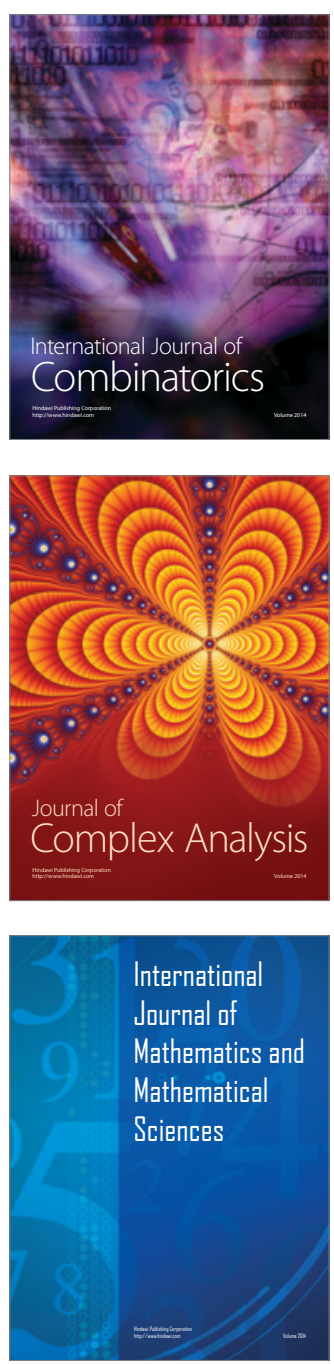
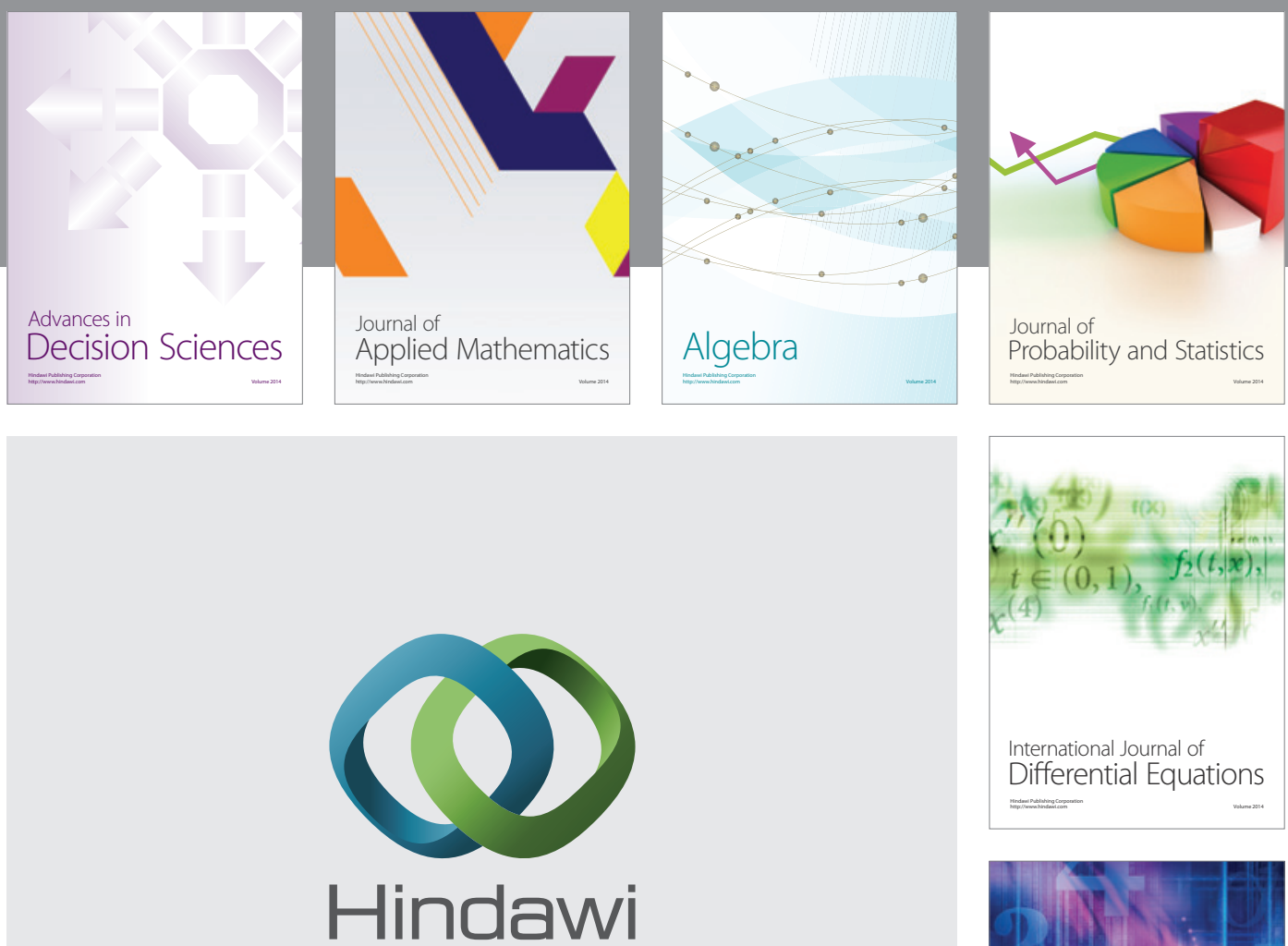

Submit your manuscripts at http://www.hindawi.com
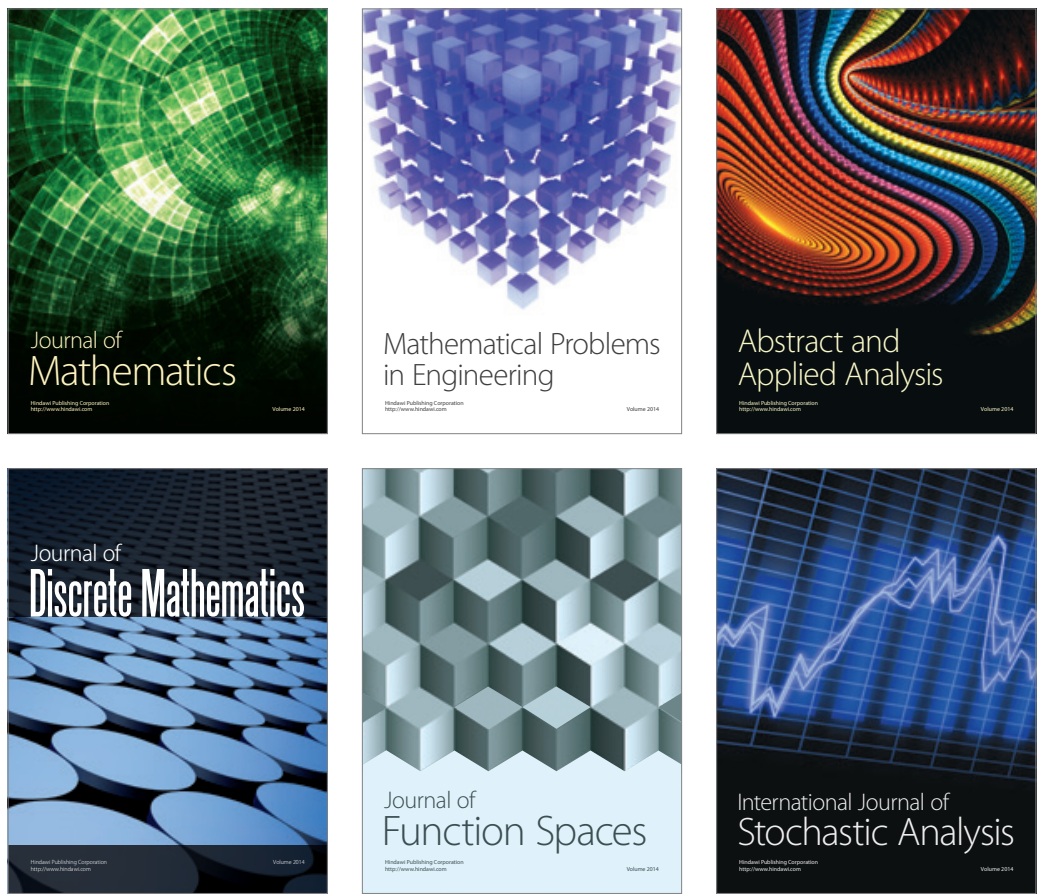

Journal of

Function Spaces

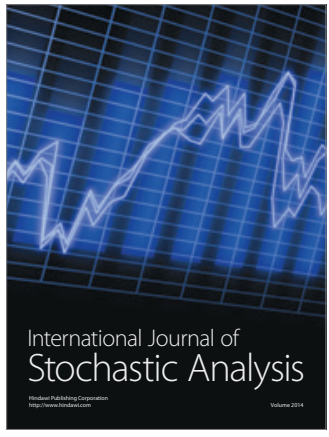

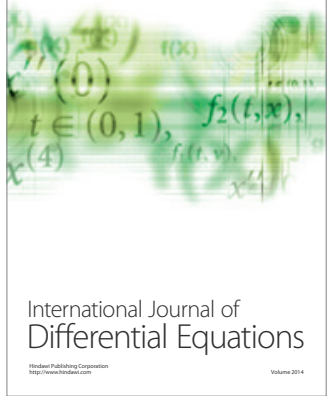
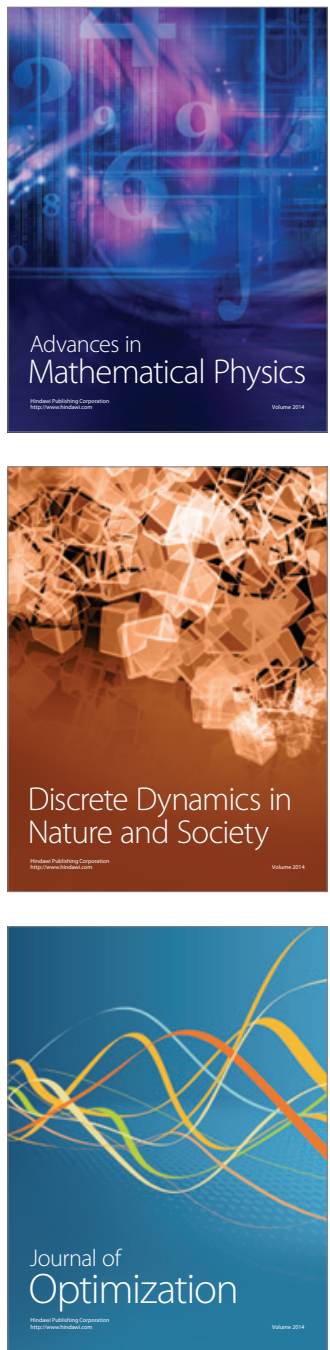